\title{
Analysis of the reliability of the fuzzy scale for assessing the students' learning styles in Mathematics
}

\author{
Ana Belén Ramos Guajardo ${ }^{1}$ María José González López ${ }^{2}$ Ignacio González Ruiz $^{2}$ \\ ${ }^{1}$ Department of Statistics, Operational Research and Mathematics Teaching, University of Oviedo, Spain \\ ${ }^{2}$ Department of Mathematics, Statistics and Computation, University of Cantabria, Spain
}

\begin{abstract}
The reliability of the fuzzy scale for assessing the responses of a person in an opinion questionnaire (which is usually treated as a Likert-type questionnaire) is analyzed. Thus, a comparison between a classical Likert scale-based questionnaire and its fuzzy rating scale-based version in terms of their reliability is established. For this purpose, some questions of the Grasha-Riechmann student learning style scales have been answered by a group of students using both scales. Considering that the Likert version of this questionnaire is reliable, the aim is to check the reliability of its fuzzy version by comparing the corresponding Cronbach's alpha coefficients.
\end{abstract}

Keywords: Fuzzy scale, reliability, Grasha Riechmann learning style scales, Cronbach's alpha coefficient

\section{Introduction}

Likert scales are widely used to measure attributes or attitudes which are often associated with opinions, perceptions, valuations and so on [18]. A Likert scale-based questionnaire leads to data chosen from a set of pre-fixed categories which are usually coded by means of integer numbers from a scale usually ranging from 1 to 5 , or from 1 to 7 .

This kind of closed format questionnaires has become very popular in practice, since they are easy to conduct and the meaning of the answers does not need to be explained in general. Nevertheless, its usefulness presents some drawbacks as it has been pointed out, for instance, in $[1,4,11,14,23]$. In the literature some authors have suggested to establish a correspondence between each Likert response category and a fuzzy value chosen from a class of flexible fuzzy sets previously stated by experts (see, for instance, $[16,17])$. Some of the drawbacks of both scales are stated below.

- Sometimes it is difficult for a person to summarize his/her perception by means of an unique value. This summary leads to a loss of information that could be useful since the subjective perceptions include certain imprecision that cannot be capture by using a single value.
- The transition from one category to another one is abrupt in general and two different categories may not be perceived in the same way by two observers.

- In addition, most of the statistical tools cannot be applied directly when Likert scales are employed and, in case it is possible, the interpretability and reliability of the results obtained is considerably reduced (see, for instance, [24]).

To overcome these problems, a way for describing each individual opinion/perception/valuation by means of a fuzzy set capturing the subjectiveness or imprecision involved in the answer and without taking into account a pre-fixed enumeration of answers has been proposed in the literature $[11,13,12,23]$.

On the other hand, the problem of detecting how students learn and acquire knowledge or skills has gained great interest in the last years (see, for instance, [9]). Most of the assessment methods for detecting a student learning style concern questionnaires in which the questions are usually associated with multiple choice answers. Regarding those methods we can found, among others, the Learning Style Inventory (ISI), where the questions have four possible answers that the students have to label from 1 to 4 according to their preference orders, and the Grasha-Riechmann Learning Style Scales (GRLSS), which is based on questions whose answers must been chosen from a Likert scale ranging from strongly disagree to strongly agree. We will center our attention in the last questionnaire which can be found in the following webpage:

http://academic.cuesta.edu/wholehealth/disted/ls_invent.htm

Lalla and others indicate in [16] that a fuzzy set system can be used as a tool for evaluating the teaching activity at different levels. In the same way, it is possible to extend this application to the evaluation of the students's learning style in a specific area/subject. It is well known that once we have introduced a measurement instrument it is necessary to evaluate its quality in terms of the validity of the construct [19]. In addition, one of the main evidences that support construct validity is the analysis of its internal structure by means of the concept of reliability [6]. 
As it is described in [5], reliability concerns the extent to which an experiment, test, or any measuring procedure yields the same results on repeated trials. It has been previously shown that the GRLLS questionnaire is reliable when the Likert scale is used for answering the questions [22]. Then, in this work we will focus our attention in the analysis of the reliability of the fuzzy scale with free response format with respect to the classical Likert scale. For this purpose, the answers given by a group of students to some questions extracted from the classical GRLSS questionnaire given in both Likert and fuzzy formats will be compared. Specifically, questions were delimited to the ones corresponding to dependent and independent learning styles in a mathematical framework. Since one of the most popular reliability statistics in use today is Cronbach's alpha [7] we will define its extension to the fuzzy case which will be useful for analyzing the reliability of the GRLSS questionnaire in the fuzzy framework.

In Section 2 some preliminaries about fuzzy sets are recalled and the Cronbach's alpha for random fuzzy sets is introduced. Section 3 is devoted to the methodology followed to collect the data using the fuzzy and the Likert formats. A comparison of the reliability of the GRLSS questionnaire when Likert and fuzzy responses are used is presented in Section 4. Finally, some conclusions and open problems are gathered in Section 5.

\section{Preliminaries}

Mathematically, a fuzzy set (or fuzzy number) $U$ is a convex function from $\mathbb{R}$ to the unit interval $[0,1]$ such that each value $x$ of $\mathbb{R}$ is associated with its membership function $U(x) \in[0,1]$. The $\alpha$-cuts or $\alpha$-levels of a fuzzy set $U$, denoted by $U_{\alpha}$, are the intervals determined by the set of values verifying $U(x) \geq \alpha$, for $\alpha \in[0,1]$. Two of the most typical shapes of fuzzy sets considered in the literature are trapezoidal and triangular, where the last one is a special case of the first one (see, for instance, $[8$, 12]).

A trapezoidal fuzzy set will be generally denoted by $\operatorname{Tr} a(a, b, c, d)$ and it satisfies that the interval $[a, d]$ is the 0 -level and $[b, c]$ is the 1-level. Mathematically, the expression for the trapezoidal fuzzy number with vertices in $\{a, b, c, d\}$ is

$$
\operatorname{Tr} a(a, b, c, d)= \begin{cases}(x-a) /(b-a) & \text { if } x \in[a, b) \\ 1 & \text { if } x \in[b, c] \\ (d-x) /(d-c) & \text { if } x \in(c, d] \\ 0 & \text { otherwise }\end{cases}
$$

A description of a trapezoidal fuzzy set and its $\alpha$-cuts is gathered in Figure 1.

The usual arithmetic between fuzzy numbers is based on Zadeh's extension principle and it agrees levelwise with the Minkowski addition and the product by scalars for compact intervals [20]. In addition, the distance between two fuzzy numbers $U$ and

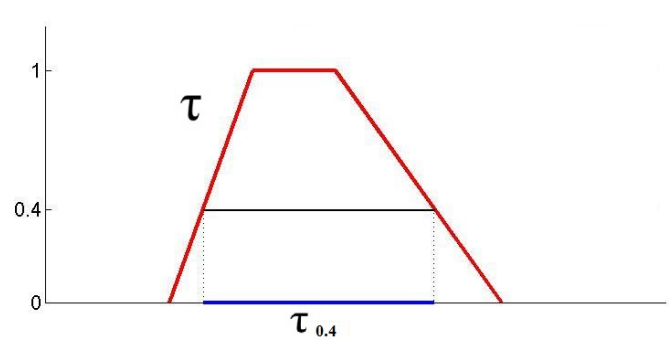

Figure 1: Representation of a trapezoidal fuzzy set

$V, D_{\theta}^{\varphi}(U, V)$, is defined by

$\sqrt{\int_{(0,1]}\left(\left(\operatorname{mid} U_{\alpha}-\operatorname{mid} V_{\alpha}\right)^{2}+\theta\left(\operatorname{spr} U_{\alpha}-\operatorname{spr} V_{\alpha}\right)^{2}\right) d \varphi(\alpha)}$,

where $\theta>0$ determines the relative weight of the distance between the spread of the $\alpha$-cuts $\left(\left(\sup U_{\alpha}-\right.\right.$ $\left.\inf U_{\alpha}\right) / 2$ ) against the distance between the corresponding mid-points $\left(\left(\sup U_{\alpha}+\inf U_{\alpha}\right) / 2\right)$. In addition, $\varphi$ is associated with a bounded density measure with support $(0,1]$ which allows us to weigh the importance given to each $\alpha$-level.

Given a probability space $(\Omega, \mathcal{A}, P)$, a random fuzzy set $\mathcal{X}$ (RFS for short) is a Borel measurable mapping with respect to $D_{\theta}^{\varphi}[21]$. If $\max \left\{\inf \mathcal{X}_{0}, \sup \mathcal{X}_{0}\right\} \in L^{1}(\Omega, \mathcal{A}, P)$, the expected value of $\mathcal{X}$ is the unique fuzzy set $E(\mathcal{X})$ so that for each $\alpha \in[0,1],(E(\mathcal{X}))_{\alpha}=\left[E\left(\inf \mathcal{X}_{\alpha}\right), E\left(\sup \mathcal{X}_{\alpha}\right)\right]$. On the other hand, if $\sup _{x \in \mathcal{X}_{0}}\|x\| \in L^{2}(\Omega, \mathcal{A}, P)$ the Fréchet-type variance ([10], or simply variance, inspired on [15]) is defined as the real value

$$
\sigma_{\mathcal{X}}^{2}=E\left(D_{\theta}^{\varphi}(\mathcal{X}, E(\mathcal{X}))\right)^{2}
$$

The sample mean is defined as in the classical theory, that is, if $\left\{\mathcal{X}_{i}\right\}_{i=1}^{n}$ is a simple random sample of size $n$ from $\mathcal{X}$, then the associated sample mean is defined as $\overline{\mathcal{X}_{n}}=(1 / n) \sum_{i=1}^{k} \mathcal{X}_{i}$. In the same way, it is possible to define the sample variance of $\left\{\mathcal{X}_{i}\right\}_{i=1}^{n}$ as $\widehat{\sigma}_{\mathcal{X}}^{2}=(1 / n) \sum_{i=1}^{n}\left(D_{\theta}^{\varphi}\left(\mathcal{X}_{i}, \overline{\mathcal{X}}_{n}\right)\right)^{2}$.

\subsection{Cronbach's alpha for RFSs}

The Cronbach's $\alpha$ [7] is a coefficient for measuring the internal consistency of a test and it is usually employed to estimate the reliability of the test scores. It takes values $\leq 1$ and it indicates the degree to which a set of items measures a single one-dimensional latent construct by analyzing the items correlation. As higher values of Cronbach's $\alpha$ are desirable, the closer to 1 the index is the more reliability of the scale.

In the classical framework, if we have $k$ items described by $k$ real random variables $X_{1}, \ldots, X_{k}$ and we have a sample of $n_{i}$ responses for each item $i \in\{1, \ldots, k\}$, the Cronbach's $\alpha$ for the corresponding measuring scale is defined as follows:

$$
\alpha=\left(\frac{k}{k-1}\right)\left(1-\frac{\sum_{i=1}^{k} \widehat{\sigma}_{X_{i}}^{2}}{\widehat{\sigma}_{T}^{2}}\right),
$$


where $\widehat{\sigma}_{T}^{2}$ is the variance of total observed values and $n=n_{1}+\ldots+n_{k}$.

In the same way, it is possible to extend the Cronbach's $\alpha$ to the fuzzy framework since the variance defined before for random fuzzy sets is a measure of the dispersion of the fuzzy values with respect to the sample mean as it is in the classical scenario. Thus, given $k$ RFSs $\mathcal{X}_{1}, \ldots, \mathcal{X}_{k}$ and $n_{i}$ responses for each item $i \in\{1, \ldots, k\}$, the Cronbach's $\widetilde{\alpha}$ for RFSs is defined as

$$
\widetilde{\alpha}=\left(\frac{k}{k-1}\right)\left(1-\frac{\sum_{i=1}^{k} \widehat{\sigma}_{\mathcal{X}_{i}}^{2}}{\widehat{\sigma}_{\mathcal{T}}^{2}}\right),
$$

where $\widehat{\sigma}_{\mathcal{T}}^{2}$ is the variance of the total observed fuzzy values.

\section{Methodology}

As it was indicated in [6], the analysis of the internal structure of a construct is usually given by the concept of reliability. In [22] it has been shown the reliability of the the GRLLS questionnaire when the Likert scale is employed. In this section, the reliability of the GRLLS questionnaire in the fuzzy context is analyzed by means of the Cronbach's $\widetilde{\alpha}$ index for RFSs.

There are two main requirements in order to check the reliability of a test [7]. First of all, the test must be composed by a set of items that can be combined in an additive way to obtain a global scoring. In addition, all the items must measure the desired feature in the same way. In our study, 20 questions have been extracted from the GRLSS questionnaire: 10 questions focussed on a dependent learning style in Mathematics and 10 questions focussed on an independent learning style in Mathematics. These questions are gathered in Table 1.

A group of 110 students attending the second course of the Degree in Primary Education of the University of Cantabria (Spain) were asked to answer these 20 questions by using both Likert and fuzzy scales.

In the first case, students choose an answer ranging from 1 to 5 to answer the questions, where 1 means totally disagree, 2 means moderately disagree, 3 means undecided, 4 means moderately agree and 10 means totally agree. In the second case, the respondents employed trapezoidal fuzzy sets in a scale ranging from 0 to 10 (where 0 represents totally disagree and 10 represents totally agree). The 0-level of each response is the set of values that the student considers compatible with his/her opinion at some extent (that is, the student considers that his/her opinion cannot be outside of this set). On the other hand, the 1-level of the trapezoidal fuzzy set is the set of values that the student considers completely compatible with his/her opinion. Finally, the corresponding limits of the 0-level and 1-level can be linearly interpolated in order to obtain a trapezoid. However, in

\begin{tabular}{|c|c|}
\hline$D_{1}$ & $\begin{array}{l}\text { I want teachers to state exactly what they } \\
\text { expect from students. }\end{array}$ \\
\hline$D_{2}$ & $\begin{array}{l}\text { I rely on my teachers to tell me what is } \\
\text { important for me to learn. }\end{array}$ \\
\hline$D_{3}$ & $\begin{array}{c}\text { I want clear and detailed instructions on } \\
\text { how to complete assignments. }\end{array}$ \\
\hline$D_{4}$ & $\begin{array}{l}\text { I complete assignments exactly the way } \\
\text { my teachers tell me to do them. }\end{array}$ \\
\hline$D_{5}$ & $\begin{array}{l}\text { Trying to decide what to study or how to } \\
\text { do assignments makes me uncomfortable. }\end{array}$ \\
\hline$D_{6}$ & $\begin{array}{l}\text { Students should be more closely } \\
\text { supervised by teachers on course projects. }\end{array}$ \\
\hline$D_{7}$ & $\begin{array}{l}\text { My notes contain almost everything the } \\
\text { teacher said in class. }\end{array}$ \\
\hline$D_{8}$ & $\begin{array}{c}\text { I prefer class sessions that are highly } \\
\text { organized. }\end{array}$ \\
\hline$D_{9}$ & $\begin{array}{l}\text { Students should be told exactly what } \\
\text { material is to be covered on exams. }\end{array}$ \\
\hline$D_{10}$ & $\begin{array}{l}\text { I want teachers to have outlines or notes } \\
\text { on the board. }\end{array}$ \\
\hline$I_{1}$ & $\begin{array}{l}\text { I prefer to work by myself on assignments } \\
\text { in my courses. }\end{array}$ \\
\hline$I_{2}$ & $\begin{array}{l}\text { My ideas about the content often are as } \\
\text { good as those in the textbook. }\end{array}$ \\
\hline$I_{3}$ & $\begin{array}{l}\text { I study what is important to me and not al- } \\
\text { ways what the instructor says is important. }\end{array}$ \\
\hline$I_{4}$ & $\begin{array}{l}\text { I learn a lot of the content in my classes } \\
\text { on my own. }\end{array}$ \\
\hline$I_{5}$ & $\begin{array}{l}\text { I feel very confident about my ability to } \\
\text { learn on my own. }\end{array}$ \\
\hline$I_{6}$ & $\begin{array}{l}\text { I like to develop my own ideas about course } \\
\text { contents. }\end{array}$ \\
\hline$I_{7}$ & $\begin{array}{l}\text { I have my own ideas about how classes } \\
\text { should be run. }\end{array}$ \\
\hline$I_{8}$ & $\begin{array}{l}\text { If I like a topic, I try to find out more } \\
\text { about it on my own. }\end{array}$ \\
\hline$I_{9}$ & $\begin{array}{l}\text { I prefer to work on class projects and } \\
\text { assignments on my own. }\end{array}$ \\
\hline$I_{10}$ & $\begin{array}{l}\text { When I don't understand something, I } \\
\text { first try to figure it out for myself. }\end{array}$ \\
\hline
\end{tabular}

Table 1: Questions regarding the dependent and independent learning styles

practice it is enough to ask the students only to indicate which are the trapezoid vertices.

There are some drawbacks to take into account whenever a fuzzy-based questionnaire is conducted. Firstly, due to the novelty of this way of answering a questionnaire a short time of training of nonexpert respondents is usually required [13]. Besides, it takes more time to answer using a fuzzy set than a value from a Likert scale which can be a shortcoming when a quick answer is demanded.

On the other hand, some arguments supporting this way of collecting data are summarized below:

- The use of the fuzzy scale entails higher diversity of responses than the Likert scale-based one, allowing the respondents to collect the 
subjectivity of their opinions in an more flexible way;

- the flexibility of the fuzzy scale implies that two different people can provide different fuzzy responses to two different questions whereas their Likert-based answers to both questions coincide;

- in the last years some statistical methods to deal with the descriptive and inferential analysis of fuzzy data have been developed (most of them have been summarized in $[2,3])$.

Figures 2 and 3 below describe the opinions of two students $A$ and $B$ given by trapezoidal fuzzy sets regarding three questions of the questionnaire. It should be remarked that the responses of both students to the same questions when they were asked to answer by using a value in a Likert scale ranging from 1 to 5 were 4,1 and 5 , respectively. This fact supports the flexibility and higher diversity of the fuzzy-type responses in contrast to the Likert ones.
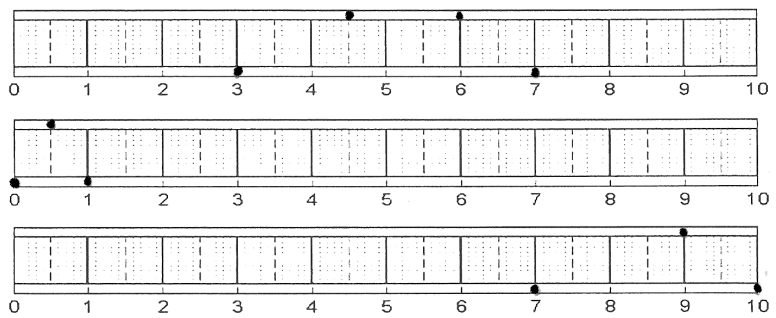

Figure 2: Opinions of the student $A$
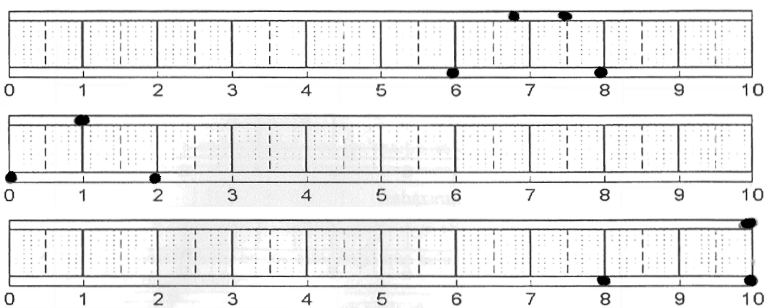

Figure 3: Opinions of the student $B$

Some experimental results are presented in the next section.

\section{Experimental results}

This section aims to compare the reliability of the GRLSS questionnaire when Likert and fuzzy responses are employed. As a first step, a descriptive analysis of the answers is presented.

Figures 4 and 6 gather the sample means of the trapezoidal fuzzy sets which encode the answers to the questions corresponding to the dependent and independent learning styles of the GRLSS questionnaire.

Furthermore, the sample means of the Likert-type answers are displayed in Table 2 below.

Although it is not possible to establish a universally acceptable complete order between fuzzy

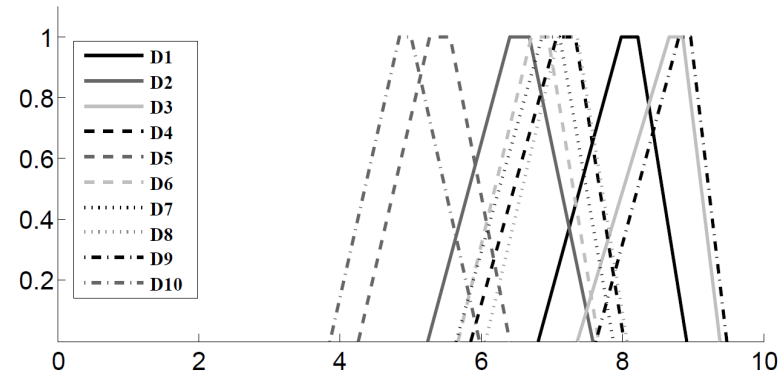

Figure 4: Sample means of the answers corresponding to the dependent learning style questions

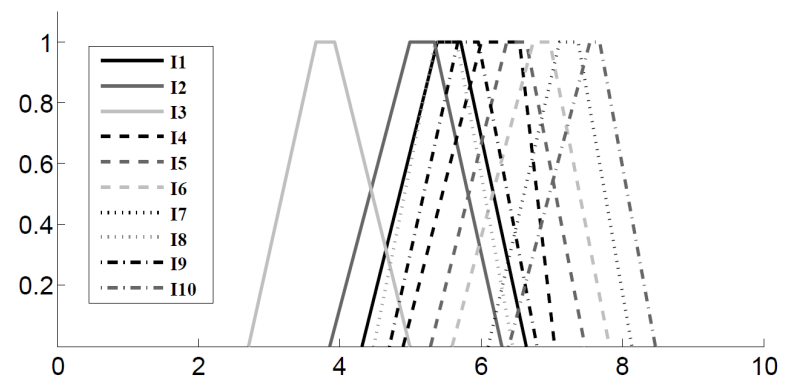

Figure 5: Sample means of the answers corresponding to the independent learning style questions

\begin{tabular}{|c||c|c|}
\hline Question & Dependent style & Independent style \\
\hline 1 & 4.194 & 3.12 \\
2 & 4.037 & 2.806 \\
3 & 4.454 & 2.407 \\
4 & 3.676 & 2.954 \\
5 & 2.852 & 3.398 \\
6 & 3.657 & 3.620 \\
7 & 3.602 & 3.611 \\
8 & 3.843 & 2.861 \\
9 & 4.593 & 3.324 \\
10 & 2.583 & 3.639 \\
\hline
\end{tabular}

Table 2: Sample means of the Likert answers

numbers [3] (since it is not straightforward to order, for instance, the trapezoidal fuzzy numbers $\operatorname{Tr} a(1,3,5,7)$ and $\operatorname{Tr} a(2,2.5,5.5,6))$, some considerations about the fuzzy-type and Likert-type sample means above should be remarked, mainly:

- Regarding the questions corresponding to the dependent learning style, if we focus our attention on the supremum of the 0-levels of the fuzzy sample means we can observe that the highest values of those supremma are reached for the questions $D_{3}$ and $D_{9}$ which are the highest means obtained for the Likert answers too. In addition, the lowest values for the infimum of the 0-levels in the fuzzy case and the lowest values of the categorical means are reached for the questions $D_{5}$ and $D_{10}$.

- On the other hand, the highest values of both the supremum of the 0-levels of the fuzzy means 
and the categorical means in the independent learning style questions correspond to questions $I_{6}, I_{7}$ and $I_{10}$ whereas the lowest values correspond to questions $I_{2}$ and $I_{3}$ in both situations.

These observations support the coherence of the fuzzy-based answers in relation to the classical categorical way of answering the GRLSS questionnaire.

Figure 6 includes the total sample mean of the dependent and independent learning style fuzzy answers.

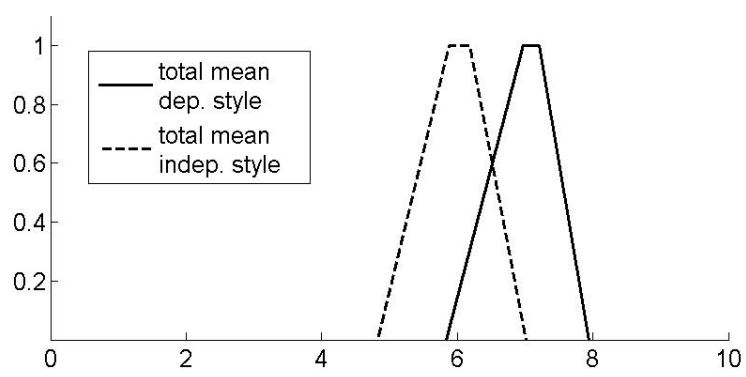

Figure 6: Sample means of the answers corresponding to the independent learning style questions

Moreover, the total sample means of the Likert answers are 3.749 and 3.174 for the dependent and independent cases, respectively. Thus, in view of results obtained in both frameworks we can conclude that the learning style of the respondents tends to be more dependent than independent in average.

Concerning the variability of the responses, the corresponding variances of the Likert and fuzzy answers for the dependent and independent learning styles are gathered in Table 3 .

\begin{tabular}{|c|c|c||c|c|c|}
\hline & Fuzzy & Likert & & Fuzzy & Likert \\
\hline$D_{1}$ & 3.261 & .879 & $I_{1}$ & 5.126 & .884 \\
$D_{2}$ & 4.392 & 1.017 & $I_{2}$ & 2.872 & .434 \\
$D_{3}$ & 1.713 & .507 & $I_{3}$ & 5.438 & .982 \\
$D_{4}$ & 2.9 & .497 & $I_{4}$ & 4.671 & .748 \\
$D_{5}$ & 5.867 & 1.293 & $I_{5}$ & 3.969 & .74 \\
$D_{6}$ & 4.967 & 1.003 & $I_{6}$ & 6.139 & 1.272 \\
$D_{7}$ & 3.56 & 0.795 & $I_{7}$ & 3.68 & .96 \\
$D_{8}$ & 4.469 & 1.003 & $I_{8}$ & 7.728 & 1.305 \\
$D_{9}$ & 1.539 & 0.501 & $I_{9}$ & 5.789 & .96 \\
$D_{10}$ & 7.597 & 1.447 & $I_{10}$ & 4.017 & .823 \\
\hline
\end{tabular}

Table 3: Sample variances in both cases

It is obvious that the variances of the Likert-type answers are smaller that the ones of the fuzzy-type answers, since the scale of variation of the answers ranges from 1 to 5 in the second case but it ranges from 0 to 10 in the first one. However, it is easy to check that in both kinds of responses the highest variances correspond to the questions $D_{10}$ and $I_{6}$ whereas the lowest ones correspond to questions $D_{9}$ and $I_{2}$. This fact corroborates the coherence between the fuzzy and Likert responses discussed before.

Finally, a comparison of the reliability of the questionnaire conducted in our experiment between the answers given by means of a value chosen from a Likert scale and the ones given in a fuzzy format is carried out. For this purpose, the classical Cronbach's alpha and the Cronbach's alpha for RFSs are computed not only considering the questions corresponding to the dependent learning style but also the ones corresponding to the independent learning style in Mathematics.

In this case, the variances of the numerators of the Cronbach's $\alpha$ and $\widetilde{\alpha}$ are the ones given in Table 3. Furthermore, the variances of the total observed values involved in the denominators, $\widehat{\sigma}_{T}^{2}$ and $\widehat{\sigma}_{\mathcal{T}}^{2}$, are computed in the set of values obtained by adding the answers of each individual to the specific learning style questions. The results of the computations are shown in Table 4.

\begin{tabular}{|c|c|c|}
\hline & Independent style & Dependent style \\
\hline$\alpha$ & .7356 & .6276 \\
$\widetilde{\alpha}$ & .7258 & .6049 \\
\hline
\end{tabular}

Table 4: Cronbach alpha for the categorical and fuzzy cases and for the dependent and independent learning styles in Mathematics

From the results observed in Table 4 it can be concluded that the Cronbach's $\alpha$ and $\widetilde{\alpha}$ are very similar on both answer formats. Nevertheless, according to a commonly accepted rule for describing the internal consistency of a test using Cronbach' alpha, it is considered to be acceptable when the index belongs to the interval $[.6, .7)$ whereas it is considered to be good when it is greater than the value .7. Thus, $\alpha$ and $\widetilde{\alpha}$ are acceptable for the dependent learning style questions using both kinds of answers and they are good for the independent learning style ones.

Despite of the fact that the values obtained in Table 4 are not very high, the most remarkable aspect is that the reliability of the questions of the GRLSS questionnaire regarding the dependent and independent learning styles is kept when fuzzy answers are provided. This implies that the employment of the fuzzy scale for answering opinion questionnaires is totally recommended since it seems to preserve the internal consistency of the test and, in addition, it presents some advantages (such as the ones described throughout this work) and it allows to better capture the intrinsic imprecision of the human opinions and perceptions.

\section{Conclusions and open problems}

In this work some questions of the GRLSS questionnaire concerning a dependent or independent learning style in Mathematics have been analyzed in terms of their internal consistency (or reliability) 
when both categorical values and fuzzy sets are provided as answers. For this purpose, a Cronbach's alpha coefficient for variables taking values in the space of fuzzy sets have been defined. The questionnaire have been conducted on students of the Faculty of Education of Cantabria (Spain). As a result, the test using fuzzy answers has been shown to be as reliable as the same test answered by using values chosen from a Likert scale. However, the fuzzy scale presents some benefits in contrast to the categorical one which make of the first scale a very appropriate tool to capture and reflect the imprecision inherent to human opinions. In addition, teachers can also be benefited from the use of the fuzzy scale since the information provided by the fuzzy questionnaire could help to improve both their teaching skills and the pointview of the subjects they teach.

As future work, a deep analysis concerning the validity and the standardization of the GRLSS questionnaire when fuzzy answers are provided is to be done. Moreover, a comparison with the classical questionnaire in terms of these two requirements is also necessary.

Acknowledgments. We would like to thank the grants "Procesos de aprendizaje del profesor de matemáticas en formación" (EDU2012-33030, Spanish Ministry of Economy and Competitiveness) and "Estadística robusta y flexible para datos intervalares, de conjunto y de conjunto difuso: localización, variabilidad y regresión lineal" (MTM201344212-P, Spanish Ministry of Economy and Competitiveness) for their financial support.

\section{References}

[1] G. Albaum, The Likert scale revisited: an alternate version, Journal of the Market Research Society, 39:331-348, 1997.

[2] A. Blanco-Fernández, M.R. Casals, A. Colubi, N. Corral, M. García-Bárzana, M.A. Gil, G. González-Rodríguez, M.T. López, M. Montenegro, M.A. Lubiano, A.B. Ramos-Guajardo, S. de la Rosa de Sáa and B. Sinova, Random fuzzy sets: a mathematical tool to develop statistical fuzzy data analysis, Iranian Journal of Fuzzy Systems, 10(2): 1-28, 2013.

[3] A. Blanco-Fernández, M.R. Casals, A. Colubi, N. Corral, M. García-Bárzana, M.A. Gil, G. González-Rodríguez, M.T. López, M. Montenegro, M.A. Lubiano, A.B. Ramos-Guajardo, S. de la Rosa de Sáa and B. Sinova, A distance-based statistical analysis of fuzzy number-valued data, International Journal of Approximate Reasoning (doi:10.1016/j.ijar.2013.09.020), in press, 2014.

[4] J. Carifio and R.J. Perla, Ten common misunderstandings, misconceptions, persistent myths and urban legends about Likert scales and Likert response formats and their antidotees, Journal of Social Sciences, 3(3): 106-116, 2007.
[5] E.G. Carmines and R.A. Zeller. Reliability and validity Asessment, Series: Quantitative applications in the social sciences, Sage Publications, Beverly Hills, 1979.

[6] D.A. Cook, T.J. Beckman, Current concepts in validity and reliability for psychometric instruments: theory and application, The American Journal of Medicine, 119:166.e7-166.e16, 2006.

[7] L.J. Cronbach, Coefficient alpha and the internal structure of tests, Psychometrika, 16:297334, 1951.

[8] D. Dubois, L. Foulloy, G. Mauris and H. Prade, Probability-Possibility transformations, triangular fuzzy sets, and probabilistic inequalities, Reliable Computing, 10(4):273-297, 2004.

[9] R. Felder and L. Silverman, Learning and teaching styles, Journal of Engineering Education, 78(7):674-681, 1988.

[10] M. Fréchet, Les éléments aléatoires de nature quelconque dan un espace distancié, Annales de l'Institut Henri Poincaré, 10:215-310, 1948.

[11] M.A. Gil and G. González-Rodríguez, Fuzzy vs. Likert scales in Statistics. In E. Trillas, P.P. Bonissone, L. Magdalena and J. Kacprzyk, editors. Combining Experimentation and Theory. A Hommage to Abe Mamdani, Studies in Fuzziness and Soft Computing 271, pages 407-420, Springer-Verlag, 2012.

[12] G. González-Rodríguez, A. Colubi and M.A. Gil, Fuzzy data treated as functional data: a one-way ANOVA test approach, Computational Statistics and Data Analysis 56:943-955, 2012.

[13] B. Hesketh, K. McLachlan and D. Gardner, Work adjustment theory: An empirical test using a fuzzy rating scale. Journal of Vocational Behavior 40: 318-337, 1992.

[14] S. Jamieson, Likert scales: how to (ab)use them, Medical Education 38(12): 1217-1218, 2004.

[15] R. Körner, On the variance of random fuzzy variables, Fuzzy Sets and Systems 92: 83-93, 1997.

[16] M. Lalla, G. Facchinetti and G. Mastroleo, Ordinal scales and fuzzy set systems to measure agreement: an application to the evaluation of teaching activity. Quality \& Quantity, 38:577601, 2004.

[17] M.A. Lazim and M.T.A. Osman, Measuring teachers' beliefs about Mathematics: a fuzzy set approach, International Journal of Social Sciences, 4(1):39-43, 2009.

[18] R. Likert, A technique for the measurement of attitudes, Archives of Psychology, 140:1-55, 1932.

[19] S. Messick. In R.L. Linn, editor. Educational Measurement, 3rd Ed. New York: American Council on Education and Macmillan, 1989.

[20] H. Minkowski. Geometrie der Zahlen, Teubner, Leipzig, 1986.

[21] M.L. Puri and D.A. Ralescu, Fuzzy random 
variables, Journal of Mathematical Analysis and Applications, 114:409-422, 1986.

[22] S.W. Riechmann and A.F. Grasha, A rational approach to developing and assessing the construct validity of a student learning style scales instrument, The Journal of Psychology: Interdisciplinary and Applied, 87(2): 213-223, 1974.

[23] S. de la Rosa de Sáa, M.A. Gil, G. GonzálezRodríguez, M.T. López and M.A. Lubiano, Fuzzy rating scale-based questionnaires and their statistical analysis, IEEE Transactions on Fuzzy Systems, in press.

[24] S.S. Stevens, On the theory of scales of measurement, Science, 103(2884):677-680. 